\title{
Osteogenic Differentiation and Biocompatibility of Bovine Teeth Scaffold with Rat Adipose-derived Mesenchymal Stem Cells
}

\author{
Desi Sandra Sari ${ }^{1,2}$ Ernie Maduratna ${ }^{3}$ Ferdiansyah ${ }^{4,5}$ Fourier Dzar Eljabbar Latief ${ }^{6} \quad$ Satuman $^{1,7}$ \\ Alexander Patera Nugraha ${ }^{1,5,8}$ Ketut Sudiana ${ }^{9,10}$ Fedik Abdul Rantam ${ }^{5,11}$
}

\footnotetext{
${ }^{1}$ Faculty of Medicine, Universitas Airlangga, Surabaya, Indonesia

2Department of Periodontics, Faculty of Dentistry, Universitas Jember, Jember, Indonesia

${ }^{3}$ Department of Periodontics, Faculty of Dental Medicine, Universitas Airlangga, Surabaya, Indonesia

${ }^{4}$ Department of Orthopaedic and Traumatology, Faculty of Medicine, Universitas Airlangga, Dr. Soetomo General Hospital, Surabaya, Indonesia

${ }^{5}$ Stem Cells Research and Development Center, Universitas Airlangga, Surabaya, Indonesia

${ }^{6}$ Micro-CT Laboratory, Faculty of Mathematics and Natural Sciences, Institut Teknologi Bandung, Bandung, Indonesia

${ }^{7}$ Laboratory of Human Physiology, Faculty of Medicine, Universitas

Brawijaya, Malang, Indonesia

${ }^{8}$ Department of Orthodontics, Faculty of Dental Medicine, Universitas Airlangga, Surabaya, Indonesia

${ }^{9}$ Department of Microscope Electron, Faculty of Medicine, Universitas Airlangga, Surabaya, Indonesia

${ }^{10}$ Department of Pathology Anatomy, Faculty of Medicine, Universitas Airlangga, Surabaya, Indonesia

${ }^{11}$ Laboratory of Virology, Department of Microbiology and Immunology, Faculty of Veterinary Medicine, Universitas Airlangga, Surabaya, Indonesia
}

Eur J Dent 2019;13:206-212
Address for correspondence Fedik Abdul Rantam, DVM, Jl. Ir H. Soekarno, Mulyosari, Campus C, Universitas Airlangga, Surabaya, Indonesia (e-mail: fedik-a-r@fkh.unair.ac.id).

\section{Abstract \\ Keywords \\ - adipose-derived mes- enchymal stem cells \\ - bovine teeth \\ - scaffold \\ - tissue engineering}

Objective Adipose-derived mesenchymal stem cells (ADMSCs) have great potential for regenerative medicine. These have been combined with biomaterials such as Bovine teeth that are preferred as a periodontal regeneration material. The main purpose of this study is to evaluate and analyze a biocompatibility test and osteogenic differentiation of bovine teeth scaffold seeded with ADMSCs in vitro.

Materials and Methods A true experimental study with post-test only group design was conducted. Random sampling and Lameshow's formula were used to determine the sample. The scaffold, obtained from bovine teeth as the bone graft material, was analyzed using 3- (4,5-dimethylthiazol-2-yl)-2,5-diphenyltetrazolium bromide (MTT) assay, and its attachment was evaluated by scanning electron microcopy (SEM) and micro-computed tomography with ADMSCs. ADMDSCs attachment present in the bovine teeth scaffold was assessed using SEM at 1-hour, 12-hour, and 24-hour intervals. Statistical Analysis Analysis of variance was used to analyze the MTT assay results $(p<0.05)$ based on normality and homogeneity test $(p>0.05)$.

Results The highest viability of cells $(97.08 \%)$ was found at a concentration of $10 \%$ by means of an MTT test $(p<0.05)$. The results of three-dimensional bovine teeth
License terms

() (1) $\odot \circledast$ 
scaffold showed the average particle size to be $500 \mu \mathrm{m}$. ADMSCs cell attachment to the scaffold bovine teeth showed a significant increase in the number of cells attached after 24 hours compared with those at 1 and 12 hours. Alizarin red staining showed an increase in ADMSC osteogenic differentiation after it was combined with bovine teeth scaffold.

Conclusion The scaffold from bovine teeth is biocompatible and accelerates osteogenic differentiation of ADMSC.

\section{Introduction}

The tissue engineering technique incorporating the use of cells and growth factors combined with scaffold for periodontal tissue regeneration is currently gaining popularity. This technique utilizes biocompatible scaffold seeds with growth factor, stem cells, or both that are implanted into a site to stimulate the reformation or repair of the missing tissues. ${ }^{1,2}$ Bovine teeth have been the most widely employed substitutes for the human variety in dental research, with their use increasing over the past 30 years. ${ }^{3,4}$ As bone graft material, bovine teeth possess osteoinductive and osteoconductive properties responsible for the construction of new bones. The term "osteoinduction" signifies that the grafted material is chemotactic to undifferentiated osteoprogenitor cells in the host and induces differentiation into osteoblasts. Osteoconduction is defined as a process that permits the growth of osteogenic cells from exposed bone surface into the adjacent graft material., 5

Bovine teeth are predominantly composed of inorganic material $(70 \%)$, organic material $(20 \%)$, and water $(10 \%)$. The inorganic component is largely hydroxyapatite and organic content consisting of collagen type I and growth factor., ${ }^{7,8}$ The purpose of scaffolds is to support cell attachment and migration, while also providing growth factors to support tissue and bone formation. The combination of scaffold and stem cells for bone growth is synergic in character. The self-renewal abilities of stem cells and their capability to differentiate into multiple cell lineages render them promising candidates for cell-based tissue engineering. Adipose-tissue derived from adult stem cells is most commonly used for periodontal regeneration..$^{10}$

Adipose-derived mesenchymal stem cells (ADMSCs) can be easily isolated, providing an enormous number of stem cells that are vital for tissue engineering and stem cells-based therapies. ${ }^{11,12}$ The International Society for Cellular Therapy set three minimum criteria for the definition of MSCs: plastic-adherence; expression of CD73, CD90, and CD105; and the absence of CD45, CD14, CD19, human leukocyte antigen - DR isotype (HLA-DR) expressions and their trilineage differentiation potential into osteoblasts, chondrocytes, adipocytes. ${ }^{13,14}$ Research into bovine teeth implantation in the calvarial defects of rats showed an increase in bone density after 6 weeks. Other research conducted by George et al state that umbilical mesenchymal stem cells demonstrate a tendency to differentiate and proliferate after binding to the tooth surface in vitro. ${ }^{15,16}$
The purpose of this study is to analyze the osteogenic potential and biocompatibility test of bovine teeth scaffold seeded with ADMSCs in vitro.

\section{Materials and Methods}

This study received ethical clearance (number 637-KE) from the Animal Care and Use Committee Faculty, Veterinary University of Airlangga, Surabaya, Indonesia. Three, 4-weekold, male Wistar rat subjects were sacrificed by euthanasia. Isolation of the ADMSCs of these subjects was performed by washing adipose tissue with saline phosphates containing $10 \%$ antimycotic-antibiotic agent. The adipose tissue was cut into pieces and immersed in a $0.2 \%$ collagenase type I (Worthington, Lakewood, New Jersey, United States) solution with the addition of Dulbecco's phosphate buffer saline (STEMCELL Technologies, Nucleos, Singapore) and agitated slowly for 40 minutes at $37^{\circ} \mathrm{C}$. The tissue was filtered using a $10 \mu \mathrm{m}$ mesh filter (Pluriselect; Leipzig, DE) before being centrifuged at 1,250 rpm for 4 minutes, with the supernatant subsequently discarded. ${ }^{17}$

\section{Isolation and Culture of Adipose-Derived Mesenchymal Stem Cells ADMSCs}

MSCs were cultured with $\alpha$-modified minimum essential medium eagle ( $\alpha$ MEM) (Gibco, Roskilde Denmark) plus 15\% fetal bovine serum (Biowest; Missouri, United States), $2 \mathrm{mM}$ of L-glutamine) (Gibco), $100 \mathrm{mg} / \mathrm{mL}$ streptomycin (Gibco), $2.5 \mu \mathrm{g} / \mathrm{mL}$ fungizone) (Gibco), and $100 \mathrm{IU} / \mathrm{mL}$ penicillin (Gibco) before being incubated at $37^{\circ} \mathrm{C}$ with $5 \% \mathrm{CO}_{2}$. The cells were grown in six wells on a tissue culture plate at a concentration of $10^{7}$ in each well. The medium was changed on the 7th day and every 3 days thereafter. Observation of the cells was performed using an inverted microscope ( $80 \times$ magnification)..$^{13-18}$

\section{Characterization ADMSCs by Immunocytochemical Staining and Flow Cytometry}

A single cell subjected to a process of trypsinization was centrifuged, fixed with formaldehyde (TCI, Chuo-ku, Tokyo), and washed with PBS. FITC anti-rat CD105 monoclonal antibody (BioLegend, San Diego, California, United States) and FITC anti-rat CD45 monoclonal antibody (BioLegend) were mixed into the sample and incubated at $37^{\circ} \mathrm{C}$ for 45 minutes. Several drops of $50 \%$ glycerin (TCI, Chuo-ku, Tokyo) were then applied to glass objects and observed under a fluorescent microscope. During the trypsinization process, the single 
cell was centrifuged. Thereafter, it was fixed in formaldehyde solution and closed with BSA. Cells were added to CD105 primary antibody and CD45 FITC. The fixed cells were analyzed by means of a FACSCalibur flow cytometer (Becton Dickinson, New Jersey, United States). ${ }^{19}$

\section{Culture on Osteogenic Medium}

MSC culture was separated using trypsin solution (Sigma, Singapore) and poured into a 24-well microplate (SPL, Gyeonggi-do, Korea) filled with osteogenic medium that contained $\alpha$ MEM medium (Gibco) with the supplementary addition of $50 \mu \mathrm{g} / \mathrm{mL}$ of L-ascorbic acid (TCI, Chuo-ku, Tokyo), 10-8 M of dexamethasone (TCI, Chuo-ku, Tokyo and $10 \mathrm{mM}$ of b-glycerophosphate (TCI, Chuo-ku, Tokyo) at a density of $2 \times 10^{5}$ and incubated at $37^{\circ} \mathrm{C}$. The medium was replaced every 3 days for 21 days. After that period, the cells were fixed with $10 \%$ formaldehyde (TCI, Chuo-ku, Tokyo), rinsed with water to facilitate examination of the osteogenic differentiation, and, finally, stained with Alizarin red (Sigma, Singapore).$^{20}$

\section{Preparation of Bovine Teeth}

Bovine teeth were cleaned with peroxidase $3 \%$ for 1 week. The crowns and roots were subsequently separated by means of a bone cutter and rongeur forceps. Powder was produced by processing the teeth comprised of dentin and cementum tissue with a bone miller. The resulting products were filtered until the desired amount was obtained. The demineralization process was performed using a bone mineral removal method involving immersion in 1\% hydrochloric acid (Merck, NJ, United States) for a day and thorough rinsing before being dried. Prior to storage, the protein content of the tooth was frozen (freeze dried = lyophilization). Particles 355 to $710 \mu \mathrm{m}$ in size were produced and sterilized in Batan, Jakarta, Indonesia. ${ }^{21}$ The bovine teeth particle shape was examined with an SEM at a magnification of $75 \times$ and 1,500× (Electron Microscope Laboratory, Faculty of Medicine, Universitas Airlangga Surabaya, East Java, Indonesia) before being scanned using micro-computed tomography (micro-CT) to observe the particle shape in three-dimensional (3D) (Faculty of Mathematics and Natural Science, Institut Teknologi Bandung West Java, Indonesia).

\section{Micro-computed Tomography-based Investigation}

The specimens were positioned in a horizontally rotating micro-CT scanning device holder (Bruker Micro-CT SkyScan 1173, High Energy Micro-CT, FMIPA ITB) before being scanned using a source X-ray voltage of $40 \mathrm{kV}$. The source current was $130 \mathrm{~mA}$ with an exposure time of $500 \mathrm{~ms}$ using a $1.0-\mathrm{mm}$ aluminum filter. The sample was scanned through a $180^{\circ}$ rotation with a rotation step of $0.2^{\circ}$. During image acquisition, 10 frames were averaged and the scanning process required approximately 2 hours per sample. By using a camera binning of $1 \times 1$, the projection images produced were $2,240 \times 2,240$ in dimension. The projection images were reconstructed as 8-bit gray scale images with isotropic spatial resolution of $5.7 \mu \mathrm{m} /$ pixel. A pre-reconstruction process, a ring artifact correction of 10 , and beam hardening correction of $20 \%$ were applied to enhance the reconstructed image quality. ${ }^{23}$

\section{Toxicity Testing}

A toxicity test (MTT assay) of bovine teeth scaffold in relation to the cell culture of ADMSCs was performed using the following procedure. Bovine teeth scaffolds were immersed in $\mu$ MEM (Gibco) for 24 hours. The pellets were cultured in ninety-six $5 \times 10^{4}$ cells/well and incubated for 24 hours at $37^{\circ} \mathrm{C}$ at $5 \% \mathrm{CO}_{2}$ concentration. After $80 \%$ growth and incubation for 20 hours at $37^{\circ} \mathrm{C}$ and $5 \% \mathrm{CO}_{2}, 200 \mu \mathrm{L}$ supernatant from bovine teeth scaffold and $25 \mu \mathrm{L}$ MTT (3- (4,5-dimethylthiazol-2-yl)-2,5-diphenyltetrazolium bromide) (Biotium, Fremont, California, United States) were added to each well and incubated for 4 hours at $37^{\circ} \mathrm{C}$. They were subsequently observed under an inverted microscope. The color change in the wells was observed with an Elisa Reader at a wavelength of $595 \mathrm{~nm} .^{22,23}$

\section{Seeding of ADMSCs on Bovine Teeth Scaffold}

Bovine teeth scaffolds were immersed in $\alpha$ MEM (Gibco) for 1 day, before the medium was removed and replaced with a new one. After 1 day, $5 \mathrm{mg}$ of bovine teeth scaffold was inserted into 96-well culture, to which a medium suspension of $2 \times 10^{6}$ cells was added and incubated for an hour at a temperature of $37^{\circ} \mathrm{C}$ and $5 \% \mathrm{CO}_{2}$. More medium was added to each $1.3 \mathrm{~mL} /$ well and incubated at a temperature of $37^{\circ} \mathrm{C}$ and $5 \% \mathrm{CO}_{2}$. The tube was periodically agitated to ensure even cell distribution within the bovine teeth scaffold suspension. SEM observation was conducted after 1 day of seeding. ${ }^{24}$

\section{Statistical Analysis}

All data were expressed as the mean and standard deviation (SD). The statistical analysis was performed using one-way analysis of variance. $p$-Value $<0.05$ was considered statistically significant.

\section{Results}

In this research, bovine teeth scaffold seeded with ADMSCs was obtained. The characteristics of bovine teeth scaffold and the viability rate of the ADMSCs was examined using MTT assays. The ADMSC culture of the subjects is shown in -Fig. 1. ADMSCs have the ability to adhere to culture plastic flasks, while they appeared, morphologically, as spindle-shaped cells both as scattered individuals and in small colonies. With regard to the expression of mesenchymal stem cell markers CD45 and CD105, based on observation under a fluorescence microscope (-Fig. 2), it transpired that CD105 expression is much stronger than that of CD45. Characterization of MSCs with flowcytometry showed that the cells cultured were MSCs with a marked subpopulation of cells expressing more CD105 than CD45.

The proportion of subpopulations of MSCs cells expressing CD105 was more dominant at 99.63\%, while that expressing CD45 accounted for only $0.37 \%$ (-Fig. 3). The effect of the bovine teeth scaffold on the mineralization ability of 
ADMSCs and the deposition of calcium and phosphate was confirmed by Alizarin red staining ( - Fig. 4 ). The morphological shape of bovine scaffold was observed in 3D using micro-CT with a particle size of 355 to $710 \mu \mathrm{m}$. - Fig. 5B shows the pore shape of the bovine teeth scaffold particles. Particle thickness distribution as estimated by means of 3D micro-CT had an average of $\sim 96 \mu \mathrm{m}$, while the average particle size as determined during the process (-Fig. 5) was 500 $\mu \mathrm{m}$. The particle size (2D) can be estimated by calculating the area and perimeter of the previously clustered objects using a watershed process (-Fig. 6). From the results of the study, the largest cell viability was obtained at a concentration of $10 \%$ with a mean \pm SD $(97.08+12.67)$, concentration of $50 \%$ with mean + SD $(88.58 \pm 12.38)$, and concentration of $100 \%$ with mean $\pm \operatorname{SD}(76.64+5.76)$ where $p<0.05$ ( - Fig. 7). The attachment and proliferation of cells on bovine teeth scaffold were demonstrated within 1,12 , and 24 hours of incubation.

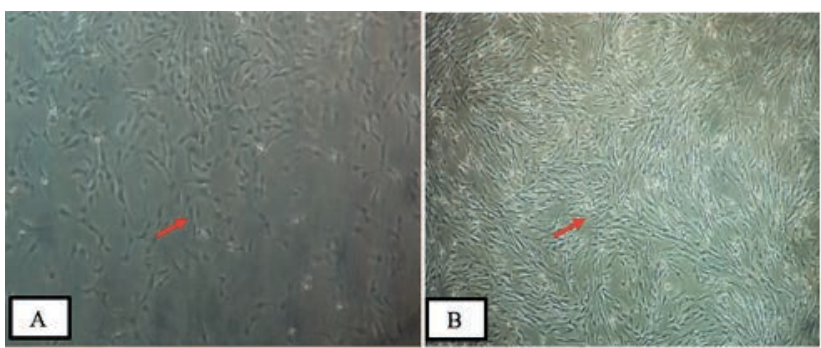

Fig. 1 Culture of adipose-derived mesenchymal stem cells (ADMSCs) showing fibroblast-like morphology and adherence to the plate: (A) Culture containing ADMSCs 1 day after isolation (passage 1 ) and (B) 15 days after isolation (passage 4) (inverted microscope at $200 \times$ magnification).

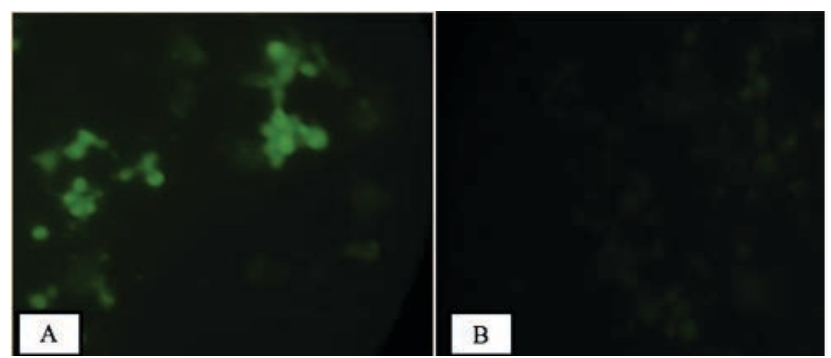

Fig. 2 The immunocytochemistry result showed that (A) adipose-derived mesenchymal stem cells are strongly expressed in CD105 and (B) weakly expressed in CD45 (immunofluorescence microscope at 200× magnification).

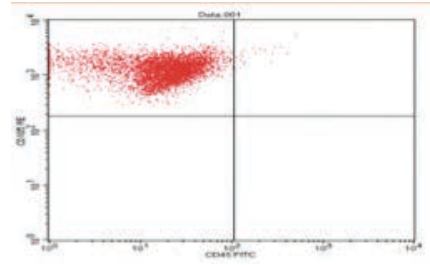

Fig. 3 Examination of flow cytometry indicating that the majority of mesenchymal stem cells subpopulations expressed more CD105 at 99.63\% (UL), while the minority subpopulations expressed around $0.37 \%$ (LL) of CD45.
After 24 hours in culture, the number of cells in the bovine teeth scaffold was greater than that at 1 and 12 hours ( $p<$ 0.05) (-Fig. 8).

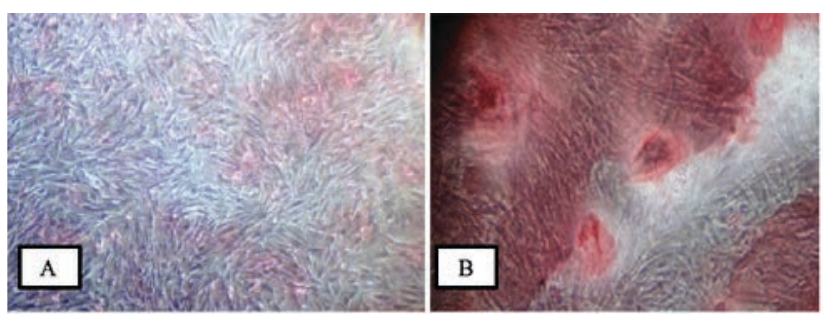

Fig. 4 Optical microscopy pictures showing the cultures stained with alizarin red. (A) Control cultured in a medium for 21 days. (B) Differentiation of adipose-derived mesenchymal stem cells as shown by positive alizarin red staining in osteogenic medium for 21 days (inverted microscope at $200 \times$ magnification).

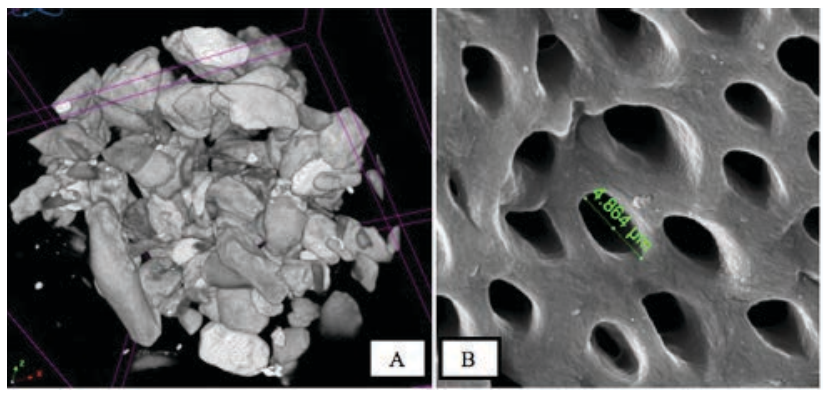

Fig. 5 (A) Bovine teeth scaffold with various particle sizes from 355 to $710 \mu \mathrm{m}$ (micro-computed tomography photographs). (B) Scanning electron microcopy photographs of bovine teeth scaffold visible pores.

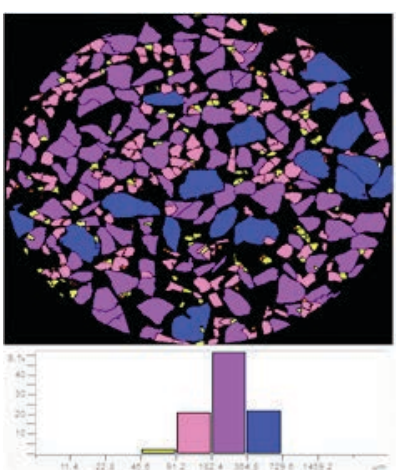

Fig. 6 Two-dimensional particle size distribution measured by the calculation of the major diameter. The majority of bovine teeth scaffold particles are 182 to $364 \mu \mathrm{m}$ (purple).

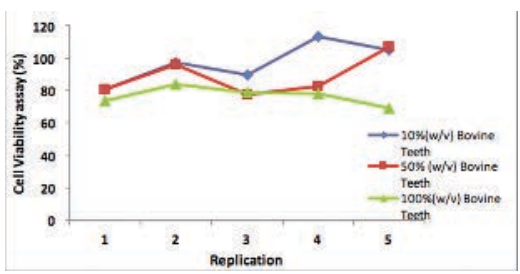

Fig. 7 Cell viability of the bovine teeth scaffold. 

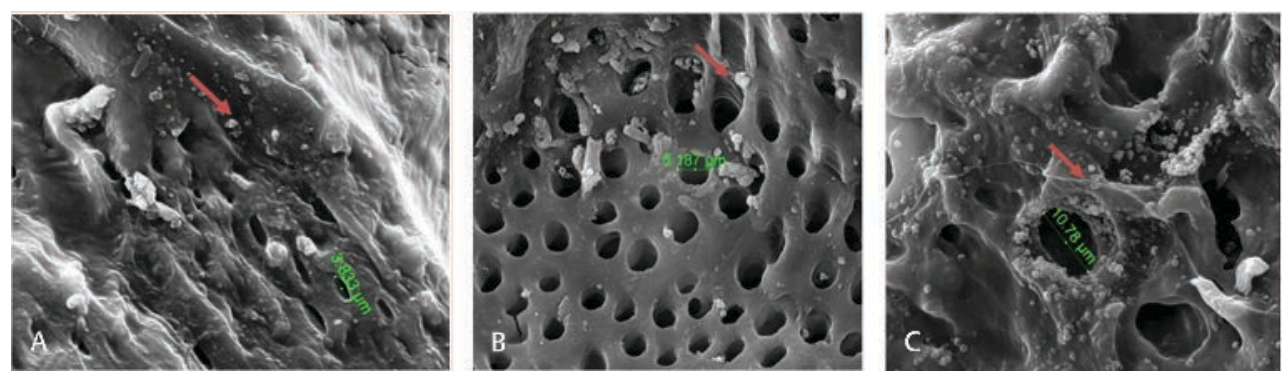

Fig. 8 Scanning electron microcopy micrographs showed adipose-derived mesenchymal stem cells seeding with bovine teeth scaffold at various time intervals: (A) 1, (B) 12, and (C) 24 hours of cells seeding DDM scaffold ( $\times 5,000$ magnification). The arrow-marked region is the attachment point.

\section{Discussion}

The growth of ADMSCs can be subcultured up to 9 to 10 passages, after which the cells will degenerate. ${ }^{25}$ ADMSCs are shown to be $80 \%$ confluent after three passages and form multilayers after $20 \times$ confluence. ${ }^{26,27}$ Periodontal tissue regeneration has also been successfully demonstrated in the experimental subject using ADMSCs. ${ }^{28}$ Characterization of ADMSCs was confirmed MSCs by means of CD105 positive and CD45 negative. CD105 is a homodimer membrane glycoprotein associated with human vascular endothelium. CD45 is expressed in hematopoietic progenitors, the small vessel endothelium of many varieties of tissue, and represents a subset of bone marrow stromal cells. ${ }^{29}$

The osteogenic differentiation of adipose-derived stem cells was initiated after as few as 4 days in the form of small nodules in isolated regions characterized by spindle-shaped cells at their perimeters. Electron microscope transmission of the osteogenic cells on day 21 of osteogenic culture showed nearly intact osteogenic progenitor cells. These are characterized by the cytoplasm that is abundant in the mitochondria, rough endoplasmic reticulum, oval-shaped mineralized calcium deposits, and the considerable numbers of collagen fibrils that are distinctive features of osteoblast differentiated cells. ${ }^{30}$ Another study posited that osteogenic differentiation requires at least 28 to 38 days at which point calcified extracellular matrix are observable after staining with alizarin red. ${ }^{31}$ The results of these experiments indicate that bovine teeth scaffold plays a crucial role in stimulating ADMSCs mineralization potential. ${ }^{32}$

Small pore size facilitates osteoblast cell proliferation, while lower porosity helps osteogenic differentiation in vitro. The structure of the newly formed bone correlated with the scaffold pore size where smaller pores support more trabeculae formation. ${ }^{33}$ There are some factors that must be considered when designing a scaffold, such as pore size, as this will affect the nutrition diffusion and migration of cells throughout the scaffold, while also influencing the formation of a vascular network within the scaffold and integration with the vascular system of the surrounding tissues. Previous studies posited that collagen combined with demineralized bone powder with a particle size of 250 to $500 \mu \mathrm{m}$ is suitable for osteoblast differentiation environments and potentially for bone tissue engineering. ${ }^{34,35}$
An MTT assay is employed to evaluate the material cytotoxicity in tissue engineering and can indicate cell growth and proliferation. These results prove that bovine teeth scaffolds are not toxic and may be attached to and proliferate in the ADMSCs. ${ }^{36}$ The HA content of bovine teeth helps improve the osteoconduction process. Inorganic materials, including HA, have also been used to promote periodontal regeneration. Hydroxyapatite can not only eliminate the morbidity of the donor site but also lead to granular migration and incomplete resorption. ${ }^{37,38}$ Previous studies have suggested that HA scaffold seeded with mesenchymal stem cells from bone marrow can improve the osteogenesis process in vivo. ${ }^{39}$ Cells were attached and spread into the pores of the scaffold, being visibly attached to the scaffold approximately 1 hour after seeding (data not shown). This result indicates that a bovine teeth scaffold is suitable for cell environments and supports cell growth and proliferation in addition to cell differentiation. ${ }^{40,41}$

\section{Conclusion}

The scaffold from bovine teeth is biocompatible and accelerates osteogenic differentiation of ADMSC.

\section{Funding}

The research was funded by doctoral dissertation research, Direktorat Jenderal Penguatan Riset dan Pengembangan, The Ministry of Research, Technology and Higher Education of The Republic of Indonesia (Kemenristekdikti RI letter of appointment agreement number 058.SP2H/LT/ DRPM/2018.

\section{Conflict of Interest}

None declared.

\section{Acknowledgments}

The authors would like to thank Team Stem Cells Research and Development Centre, Universitas Airlangga; Laboratory of Animal Experimental Stem Cells Research and Development Centre, Universitas Airlangga; Postgraduate School, Faculty of Medicine, Universitas Airlangga; and the Micro-CT Laboratory (Bruker Micro-CT SkyScan 1173) of the Faculty of Mathematics and Natural Science, Institut Teknologi Bandung. 


\section{References}

1 Amal SP, Yash M, Preeti N. Tissue engineering of craniofacial tissues-a review. Regen Med Tissue Eng. 2013;2(6):1-19

2 Siddhartha VA, Shartak B, Rashmi G, Shilpa S, Uzma B. Tissue engineering in periodontics-a novel therapy. Ann Dental Res 2012;2(1):01-07

3 Young-Kyun K. Bone graft material using teeth. J Korean Assoc Oral Maxillofac Surg 2012;38:134-138

4 Teruel JdeD, Alcolea A, Hernández A, Ruiz AJ. Comparison of chemical composition of enamel and dentine in human, bovine, porcine and ovine teeth. Arch Oral Biol 2015;60(5):768-775

5 de Oliveira GS, Miziara MN, Silva ER, Ferreira EL, Biulchi APF, Alves JB. Enhanced bone formation during healing process of tooth sockets filled with demineralized human dentine matrix. Aust Dent J 2013;58(3):326-332

6 Amini AR, Laurencin CT, Nukavarapu SP. Bone tissue engineering: recent advances and challenges. Crit Rev Biomed Eng 2012;40(5):363-408

7 Koga T, Minamizato T, Kawai Y, et al. Bone regeneration using dentin matrix depends on the degree of demineralization and particle size. PLoS One 2016;11(1):e0147235

8 Monthira S. Dentin as bone graft substitution. Songklanakarin Dent J 2014;2(1):21-27

9 Kim YK, Lee J, Um IW, et al. Tooth-derived bone graft material. J Korean Assoc Oral Maxillofac Surg 2013;39(3):103-111

10 Nassif L, El Sabban M. Mesenchymal stem cells in combination with scaffolds for bone tissue engineering. Materials (Basel) 2011;4(10):1793-1804

11 Baer PC, Werner L, Adipose-derived stromal/stem cells and their differentiation potential into the endothelial lineage. In: Jurgen H, Erhard H eds. Adult and Pluripotent Stem Cells. Köln, Germany: Springer; 2014:53-64

12 Lotfy A, Salama M, Zahran F, Jones E, Badawy A, Sobh M. Characterization of mesenchymal stem cells derived from rat bone marrow and adipose tissue: a comparative study. Int J Stem Cells 2014;7(2):135-142

13 Dominici M, Le Blanc K, Mueller I, et al. Minimal criteria for defining multipotent mesenchymal stromal cells. The International Society for Cellular Therapy position statement. Cytotherapy 2006;8(4):315-317

14 Chiho I, Ken S, Mesenchymal Stem Cells for Regenerative Therapy: Optimization of Cell Preparation Protocols. Hindawi Publishing Corporation BioMed Research International. 2014:1-11

15 Ibrahim H, Keyvan M, Ian MB, Patrıcio JON, Luiz AS, Evaluation of Osteoconductive and Osteogenic Potential of a Dentin-Based Bone Substitute Using a Calvarial Defect Model. Hindawi Publishing Corporation International Journal of Dentistry, 2012;1-6

16 George JP, Chakravarty P, Chowdhary KY, Purushothama H, Rao JA. Attachment and differentiation of human umbilical cord stem cells on to the tooth root surface with and without the use of fibroblast growth factor-an in vitro study. Int J Stem Cells 2015;8(1):90-98

17 Rada T, Gomes ME, Reis RL. A novel method for the isolation of subpopulations of rat adipose stem cells with different proliferation and osteogenic differentiation potentials. J Tissue Eng Regen Med 2011;5(8):655-664

18 Kamal D, Iskandriati I, Dilogo N, et al. Comparison of culture mesenchymal stem cell derived from bone marrow or peripheral blood of rats. J Exp Integr Med 2014;4(1):17-22

19 Martens W, Wolfs E, Struys T, Politis C, Bronckaers A, Lambrichts I. Expression pattern of basal markers in human dental pulp stem cells and tissue. Cells Tissues Organs 2012;196(6):490-500
20 Birmingham E, Niebur GL, McHugh PE, Shaw G, Barry FP, McNamara LM. Osteogenic differentiation of mesenchymal stem cells is regulated by osteocyte and osteoblast cells in a simplified bone niche. Eur Cell Mater 2012;23:13-27

21 Nather YN, Hilmi N. Allograft Procurement Processing and Transplantation: A Comprehensive Guide for Tissue Bank. Singapore: World Scientific Publishing Co. Pvt Ltd.; 2010;356-358

22 Ola SM. Preparation and characterization of hydroxyapatite from bovine teeth. Nat Appl Sci 2017;11(8):623-630

23 David BK, Purwati, Fedik AR, Ferdiansyah, Coen DP. Healing mechanism and osteogenic capacity of bovine bone mineral-human amniotic mesenchymal stem cell and autogenous bone graft in critical size mandibular defect. J Biomed Sci Eng 2015;8:733-746

24 Yaling S, Jerry NR, Adrain SB, Simon B, Brend LA. Adipose-derived stem cells combined with a demineralized cancellous bone substrate for bone regeneration. Tissue Eng 2012;18(13):1-9

25 Jin GZ, Park JH, Wall I, Kim HW. Isolation and culture of primary rat adipose derived stem cells using porous biopolymer microcarriers. Tissue Eng Regen Med 2016;13(3):242-250

26 Seyed JH, Hamed G, Ahmad G, Hamid RS, Majid GM, Elaheh M. Isolation characterization and differentiation of rat adipose tissue derived mesenchymal stem cells. Int J Pediatr 2014;2(Suppl 3):1-6

27 Uccelli A, Moretta L, Pistoia V. Mesenchymal stem cells in health and disease. Nat Rev Immunol 2008;8(9):726-736

28 Cao F, Liu T, Xu Y, Xu D, Feng S. Culture and properties of adipose-derived mesenchymal stem cells: characteristics in vitro and immunosuppression in vivo. Int J Clin Exp Pathol 2015;8(7):7694-7709

29 Kawashima N. Characterisation of dental pulp stem cells: a new horizon for tissue regeneration? Arch Oral Biol 2012;57(11):1439-1458

30 Hassan IHE, Mohamed AS, Soad AK, Omnia KRE. Adipose derived mesenchymal stem cell differentiation into adipogenic and osteogenic stem cells. Stud Stem Cells Res Ther 2011;2(1):17-24

31 Locke M, Windsor J, Dunbar PR. Human adipose-derived stem cells: isolation, characterization and applications in surgery. ANZ J Surg 2009;79(4):235-244

32 Li TX, Yuan J, Chen Y, et al. Differentiation of mesenchymal stem cells from human umbilical cord tissue into odontoblast-like cells using the conditioned medium of tooth germ cells in vitro. BioMed Res Int 2013; $2013: 1-10$

33 Sundelacruz S, Kaplan DL. Stem cell- and scaffold-based tissue engineering approaches to osteochondral regenerative medicine. Semin Cell Dev Biol 2009;20(6):646-655

34 Thitiset T, Damrongsakkul S, Bunaprasert T, Leeanansaksiri W, Honsawek S. Development of collagen/demineralized bone powder scaffolds and periosteum-derived cells for bone tissue engineering application. Int J Mol Sci 2013;14(1):2056-2071

35 da Cruz GA, de Toledo S, Sallum EA, de Lima AF. Morphological and chemical analysis of bone substitutes by scanning electron microscopy and microanalysis by spectroscopy of dispersion energy. Braz Dent J 2007;18(2):129-133

36 Chen $\mathrm{Q}$ Shou P, Zheng C, et al. Fate decision of mesenchymal stem cells: adipocytes or osteoblasts? Cell Death Differ 2016;23(7):1128-1139

37 Darby I. Periodontal materials. Aust Dent J 2011;56(Suppl 1): 107-118

38 Hidetoshi S, Eiji N, Hiroshi S, Masatsugu S. Possible functional scaffold for periodontal regeneration. Jpn Dent Sci Rev 2013;49:118-130 
39 Li Z, Yossy M, Yanging W, Yayou L, Seeram R. Review scaffold design and stem cells for tooth regeneration. Jpn Dent Sci Rev 2013;9:14-26

40 Weiguang W, Guilherme C, William SA, et al. Enhancing the hydrophilicity and cell attachment of 3D printed PCL/ graphene scaffold for bone tissue engineering. Materials (Basel) 2016;9(992):1-10
41 Supronowicz P, Gill E, Trujillo A, et al. Human adiposederived side population stem cells cultured on demineralized bone matrix for bone tissue engineering. Tissue Eng Part A 2011;17(5-6):789-798 